complaints were diagnosed with bronchitis. This resulted in a more frequent use of inhaled steroids and bronchodilators in Dutch children as compared with German children [2].

We cannot exclude the fact that a possible geographically heterogeneous worldwide Chlamydia pneumoniae pandemic could contribute to changes in asthma prevalences in different countries. However, it seems unlikely to us that this would be the sole explanation, as not all asthmatics (established or newly diagnosed) have C. pneumoniae present in bronchoalveolar lavage fluid. Moreover, the widespread use of (macrolide) antibiotics has not prevented a clear increase in asthma prevalence. On the contrary, it seems that a decrease in hospitalisation and mortality is strongly associated with an increase in the use of inhaled steroids [3], and there is no indication that this is associated with the use of antibiotics.

However, it is certainly worthwhile to pay attention to the socalled Chlamydia-asthma theory proposed by D.L. Hahn and to investigate the presence of Chlamydia pneumoniae or other infectious organisms in new asthma patients.
C.P. van Schayck, M. Mommers and E.D. Dompeling

Care and Public Health Research Institute (CAPHRI), University Maastricht, Maastricht, The Netherlands.

\section{REFERENCES}

1 van Schayck CP, van der Heijden FM, van den Boom G, Tirimanna PRS, van Herwaarden CL. Underdiagnosis of asthma: is the doctor or the patient to blame? The DIMCA project. Thorax 2000; 55: 562-565.

2 Mommers M, Swaen GMH, Weishoff-Houben M, Dott W, van Schayck CP. Differences in asthma diagnosis and medication use in children living in Germany and the Netherlands. Prim Care Respir J 2005; 14: 31-37.

3 Haahtela T, Klaukka T, Koskela K, Erhola M, Laitinen LA. Asthma programme in Finland: a community problem needs community solutions. Thorax 2001; 56: 806-814.

DOI: $10.1183 / 09031936.06 .00129205$

\title{
Nasogastric tube feeding is a cause of aspiration pneumonia in ventilated patients
}

\section{To the Editors:}

In a recent issue of the European Respiratory Journal, KosTADIMA et al. [1] reported that early gastrostomy is associated with a lower frequency of ventilator-associated pneumonia (VAP) compared with nasogastric tube (NGT) feeding in patients who are mechanically ventilated due to stroke or head injury. Since VAP is the most frequent and serious intensive care unit (ICU)acquired infection among patients undergoing mechanical ventilation, and is associated with a $20-30 \%$ increase in the risk of death, the preventive strategy for VAP in mechanically ventilated patients is important to reduce the length of an ICU stay and overall mortality [2].

Although the classic theories, including the gastropulmonary hypothesis, are important to understand the mechanisms of VAP, the recent advancement of the pathophysiology of nosocomial pneumonia and aspiration pneumonia are not fully discussed in the paper by Kostadima et al. [1].

There is growing evidence that oropharyngeal dysphagia plays a critical role in aspiration pneumonia and VAP in mechanically ventilated patients [3, 4]. Brain injury, severe stroke and unconsciousness, due to sedatives and hypnotics, disturb the swallowing reflex. This results in the development of aspiration pneumonia in humans and animals [5]. However, nosocomial pneumonia and aspiration pneumonia are prevented by the improvement of the swallowing reflex after administration of angiotensin-converting enzyme (ACE) inhibitors [6]. The elevated levels of bradykinin and substance P by ACE inhibitors play a role in setting the threshold for the cough and swallowing reflex in humans, resulting in the reduction of occurrence of pneumonia. Although KosTADIMA et al. [1] speculated about the underlying mechanisms of risk of VAP in the patients with NGT feeding, they did not assess the swallowing reflex and cough reflex. We have developed a novel diagnostic test for the risk of aspiration pneumonia [7, 8]. The simple swallowing provocation test can be applied for all the ventilated patients as it is very easy and can be performed on bedridden patients without requiring their cooperation. The assessment of the swallowing reflex is the clue to the underlying mechanisms of VAP in critically ill patients. As it has been suggested that nosocomial maxillary sinusitis increases the occurrence of VAP, microaspiration of oropharyngeal materials, including maxillary sinus, is a significant cause of VAP [9].

NGT feeding is known to be a significant cause of aspiration pneumonia in stroke patients [10]. Since the NGT bypasses the small amount of gastric contents through to the oropharynx, the materials can be easily aspirated into lower airways in dysphagic patients with stroke. The mechanism is not related to the percutaneous endoscopic gastrostomy (PEG). This evidence supports the fact that NGT feeding, but not PEG, is a significant cause of VAP in critically ill patients. Although feeding via PEG is a very straightforward way to reduce aspiration and aspiration-associated pneumonia, the improvement of the swallowing reflex must be a fundamental approach to reduce VAP in patients. As the PEG procedure using gastroscopic fibre may also be a risk for aspiration in unconscious patients, the indication of early gastrostomy for 
the patients should be very carefully assessed. The PEG feeding patients with dysphagia may be suffering from aspiration pneumonia [11].

Considered together, we believe that the prevention of aspiration by using oral care, angiotensin-converting enzyme inhibitors and swallowing rehabilitation may be an alternative approach in reducing the risk of ventilator-associated pneumonia in patients.

\section{S. Teramoto*, T. Ishii ${ }^{\#}$, H. Yamamoto*, Y. Yamaguchi* and Y. Ouchi*}

*Dept of Geriatric Medicine, University of Tokyo, Tokyo, and "Pulmonary Medicine, Yokohama City University, Yokohama, Japan.

\section{REFERENCES}

1 Kostadima E, Kaditis AG, Alexopoulos EI, Zakynthinos E, Sfyras D. Early gastrostomy reduces the rate of ventilatorassociated pneumonia in stroke or head injury patients. Eur Respir J 2005; 26: 106-111.

2 Povoa P, Coelho L, Almeida E, et al. C-reactive protein as a marker of ventilator-associated pneumonia resolution: a pilot study. Eur Respir J 2005; 25: 804-812.

3 Teramoto S, Yamamoto H, Yamaguchi Y, Kawaguchi H, Ouchi Y. Nosocomial infections in adult intensive-care units. Lancet 2003; 362: 493.

4 Teramoto $S$. The causes of aspiration pneumonia in mechanically ventilated patients: a possible pathological link with upper airway bacterial colonization. $\mathrm{Br}$ J Anaesth 2000; 84: 694.

5 Teramoto S, Matsuse T, Ishii T, Matsui H, Fukuchi Y, Ouchi $Y$. Investigation of age on the aspiration using LacZ gene transduction of adenovirus vectors. Am J Respir Crit Care Med 1998; 158: 1914-1919.

6 Teramoto S, Ouchi Y. ACE inhibitors and prevention of aspiration pneumonia in elderly hypertensives. Lancet 1999; 353: 843.

7 Teramoto S, Yamamoto H, Yamaguchi Y, Ouchi Y, Matsuse T. A novel diagnostic test for the risk of aspiration pneumonia in the elderly. Chest 2004; 125: 801-802.

8 Teramoto S, Matsuse T, Fukuchi Y, Ouchi Y. Simple twostep swallowing provocation test for elderly patients with aspiration pneumonia. Lancet 1999; 353: 1243.

9 Holzapfel L, Chastang C, Demingeon G, Bohe J, Piralla B, Coupry A. A randomized study assessing the systematic search for maxillary sinusitis in nasotracheally mechanically ventilated patients. Influence of nosocomial maxillary sinusitis on the occurrence of ventilator-associated pneumonia. Am J Respir Crit Care Med 1999; 159: 695-701.

10 Ferrer M, Bauer TT, Torres A, Hernandez C, Piera C. Effect of nasogastric tube size on gastroesophageal reflux and microaspiration in intubated patients. Ann Intern Med 1999; 130: 991-994.

11 Carnes ML, Sabol DA, DeLegge M. Does the presence of esophagitis prior to PEG placement increase the risk for aspiration pneumonia? Dig Dis Sci 2004; 49: 1798-1802.
From the authors:

We read with interest the letter from S. Teramoto and coworkers regarding the role of oropharyngeal dysphagia in the pathogenesis of ventilator-associated pneumonia (VAP). The presence of a nasogastric tube has been identified as an independent risk factor for VAP, mainly because of gastrooesophageal reflux and aspiration [1,2]. Aspiration is probably due to loss of anatomical integrity of the lower oesophageal sphincter, increased frequency of transient sphincter relaxation and oropharyngeal dysphagia via desensitisation of the pharyngoglottal adduction reflex [3,4].

We speculate that the advantage of performing an early gastrostomy is the possibility of avoiding dysfunction of lower oesophageal sphincter due to the presence of a nasogastric tube [5]. JoHNSON et al. [6] have demonstrated an increase in lower oesophageal sphincter pressure following performance of percutaneous endoscopic gastrostomy and a decrease in gastro-oesophageal reflux score. Prevention of oropharyngeal dysphagia induced by the nasogastric tube may be another mechanism in reducing the risk of aspiration.

Of note, percutaneous endoscopic gastrostomy does not eliminate gastro-oesophageal reflux, mainly in patients with a pre-existing nasogastric tube [7]. For this reason, we selected the performance of early gastrostomy in our study. In a recent report, MCCLAVE et al. [8] found a decrease in the incidence of regurgitation in intensive care unit patients with early gastrostomy compared with those with a nasogastric tube.

\section{E. Kostadima, A. Kaditis, E. Alexopoulos, E. Zakynthinos and D. Sfyras}

University of Thessaly School of Medicine and Larissa University Hospital, Larissa, Greece.

\section{REFERENCES}

1 Tablan OC, Anderson LJ, Besser R, Bridges C, Hajjeh R. Guidelines for preventing health-care-associated pneumonia, 2003: recommendations of the CDC and the Health-care Infection Control Practices Advisory Committee. MMWR Recomm Rep 2004; 53: 1-36.

2 Chastre J, Fagon J-Y. Ventilator-associated pneumonia. Am J Respir Crit Care Med 2002; 165: 867-903.

3 Gomes GF, Pisani JC, Macedo ED, Campos AC. The nasogastric feeding tube as a risk factor for aspiration and aspiration pneumonia. Curr Opin Clin Nutr Metab Care 2003; 6: 327-333.

4 Nind G, Chen W, Protheroe R, et al. Mechanisms of gastroesophageal reflux in critically ill mechanically ventilated patients. Gastroenterology 2005; 128: 600-606.

5 Kostadima E, Kaditis AG, Alexopoulos EI, Zakynthinos E, Sfyras D. Early gastrostomy reduces the rate of ventilatorassociated pneumonia in stroke or head injury patients: a preliminary study. Eur Respir J 2005; 26: 106-111.

6 Johnson DA, Hacker JF, Benjamin SB, et al. Percutaneous endoscopic gastrostomy effects on gastroesophageal reflux 